\title{
The relevance of trunk evaluation in Duchenne muscular dystrophy: the segmental assessment of trunk control
}

\author{
A relevância da avaliação do controle de tronco na distrofia muscular de Duchenne: \\ a Segmental Assessment of Trunk Control \\ Cristina dos Santos Cardoso de Sá , lara Kristine Fagundes², Talita Bastos Araújo², Acary Souza Bulle \\ Oliveira ${ }^{3}$, Francis Meire Fávero ${ }^{3}$
}

\begin{abstract}
The aim was to describe trunk control in ambulant and non-ambulant patients with Duchenne muscular dystrophy (DMD). We conducted a cross-sectional analysis of a sample of 50 DMD patients, ( $M$ age $=16.7$ years) who underwent the Segmental Assessment of Trunk Control (SATCO). A seven-level scale of trunk control was used (1: head control only; 7: control of entire trunk while unsupported). Static, active and reactive posture control were evaluated in ambulant and non-ambulant patients. Inter-rater reliability for all assessments was evaluated by calculating the kappa coefficient. More advanced disease (having higher Vignos scores), was associated with poorer trunk control. Ambulant patients showed better trunk control than non-ambulant patients $(p=0.003)$. There was strong inter-rater agreement for SATCo scale scores.
\end{abstract}

Keywords: muscular dystrophy, Duchenne; physical therapy specialty; evaluation.

\section{RESUMO}

O objetivo foi avaliar o controle de tronco em pacientes deambulantes e não-deambulantes com distrofia muscular de Duchenne (DMD). Estudo transversal composto por 50 pacientes com diagnóstico de DMD, média de idade 16,72 anos, avaliados pela Segmental Assessment of Trunk Control (SATCO). A escala apresenta sete níveis para o controle de tronco incluindo-se desde o controle de cabeça até controle de tronco total em que o paciente permanece sem apoio. Controle estático, ativa e reativa de postura do tronco foram avaliados em pacientes deambulantes e não-deambulantes. Para a confiabilidade entre os avaliadores, empregou-se a análise estatística Kappa. Quanto maior a pontuação na escala Vignos, maior a frequência de pacientes com DMD que apresentam pior controle de tronco. Pacientes deambulantes apresentaram controle de tronco melhor do que os pacientes não-deambulantes $(p=0,003)$. Houve forte confiabilidade entre avaliadores para a pontuação da escala SATCo.

Palavras-chave: distrofia muscular de Duchenne; fisioterapia; avaliação.

Duchenne muscular dystrophy (DMD) is characterised by muscle strength loss that initially affects the muscles of the pelvic girdle and lower limbs, progressing to trunk muscles and the muscles responsible for maintaining a standing posture ${ }^{1}$. Trunk muscle imbalance occurs in this population as muscle weakness progresses; this can be directly responsible for postural abnormalities, e.g. as a result of imbalance in paraspinal muscles, or indirectly responsible as muscle contractures lead to postural compensations when standing and sitting and gait asymmetries. Trunk alterations cause spinal deformities that have a detrimental effect on functional independence, postural control and balance ${ }^{2}$.

Postural control is the main requirement for maintaining one's body in a steady state ${ }^{2,3,4}$. Maintaining strength in the trunk muscles is essential to activities such as sitting, standing, walking and manual activities ${ }^{5}$. An analysis of DMD patients' independence in activities of daily living showed that most patients could feed themselves independently, but needed dressing, undressing and personal hygiene assistance ${ }^{6}$. The latter activities require more complex postural changes, which makes them more difficult for patients with DMD, due to trunk and limb instability.

\footnotetext{
'Universidade Federal de São Paulo, Departamento de Ciências do Movimento Humano, São Paulo SP, Brasil;

Universidade Federal de São Paulo, São Paulo SP, Brasil;

${ }^{3}$ Universidade Federal de São Paulo, Departamento de Neurologia/Neurocirurgia, São Paulo SP, Brasil.

Correspondence: Cristina dos Santos Cardoso de Sá; Rua Silva Jardim, 136; 11015-020 Santos SP, Brasil; E-mail: cristina.sa@uol.com.br

Conflict of interest: There is no conflict of interest to declare.

Received 10 August 2015; Received in final form 08 January 2016; Accepted 20 June 2016
} 
A new tool for assessing trunk control, the Segmental Assessment of Trunk Control (SATCo), is now available and can be used to evaluate trunk control in patients in the early stages of $\mathrm{DMD}^{7,8}$. It can also be used to improve balance in the sitting position and increase the length of time the individual can remain stable while seated, thus slowing the progressive loss of motor function.

This aim of this study was to evaluate trunk control in ambulant and non-ambulant patients with DMD and to determine the inter-rater reliability of SATCo.

\section{METHODS}

This was a cross-sectional study of 50 patients with DMD followed in the Brazilian Muscular Dystrophy Association in the state of São Paulo, in the south-eastern region of Brazil. The diagnoses were based on muscle biopsy findings and/or DNA tests. The age of the sample ranged from eight to 27 years, with a mean age of 16.7 years $( \pm 4.4)$. Patients with other types of muscular dystrophy, patients who did not have a minimum level of head control, patients who had undergone spinal surgery less than six months before and patients who had difficulty understanding the study protocol were excluded. The study was approved by the Ethics Committee.

Disease progression was evaluated by the Vignos $^{9}$ scale. The Vignos scale is a ten-point scale ranging from 1 , which indicates a small detectable change in posture, to 10, which indicates confinement to bed and inability to perform activities of daily living without assistance. Ambulant patients score 1-6 and non-ambulant patients score 7-10 on Vignos scale.

The $\mathrm{SATCo}^{7}$ is a method for evaluating trunk control of patients with motor impairment of neurological cause. For the SATCo application, an appropriate bench is used. The bench has a system of attachment straps to ensure that the pelvis remains in a neutral position and the patient is supported manually by the evaluator. The evaluator progressively reduces the patient's contact support to determine the level of support required to maintain the seated posture.

The SATCo involves seven levels of trunk control (1 to 7). The trunk control assessment begins by assessing head control (level 1), when the examiner supports the patient's shoulder girdle and the patient rests the upper limbs on a table surface to provide stability and support. Level 2 represents upper chest control. It is assessed by the evaluator's support under the patient's armpits. Level 3 represents medium thoracic control. The evaluator positions his or her hands below the patient's scapula. Level 4 represents lower chest control. The evaluator supports the patient by placing his or her hands on the patient's lower ribs. Level 5 represents upper lumbar control. The evaluator positions his or her hands below the patient's ribs. Level 6 represents lower lumbar control. The evaluator supports the patient's pelvis. Level 7 represents full trunk control. The patient is able to maintain a stable, seated position without the support of the evaluator or brace system. During levels 2 to 7 of the assessment, the patient is required to keep his or her upper limbs in abduction with elbow flexion, without using a table surface for support.

At each level - or trunk segment - the patient's ability to maintain, or quickly recover, a vertical position is evaluated during static, active and reactive posture control. Motor responses are classified as 'present', 'absent' or 'not tested'.

Static control is present if the patient can maintain a neutral trunk posture above the level of support from the examiner's hands for five seconds; active control is present if the patient can maintain the neutral posture during head motion associated with maintaining elevated arms; reactive control is present if the patient can recover the neutral trunk position quickly after an external disturbance. The evaluator applies external disturbance to the trunk, always at the same horizontal level, in four directions: anterior - manubrium of the sternum; posterior - on the C7 vertebra; on the right and left - shoulder parallel to the acromion. The highest level at which static, active and reactive control of trunk posture are present is taken as the level of trunk control.

The scale is also used to evaluate the presence or absence of deformity in the spine in terms of scoliosis, lordosis and kyphosis and to note limitations to cervical movement. Limitation is noted if the patient is unable to move the neck at an angle greater than $45^{\circ}$ horizontally.

\section{Statistical analysis}

The tests were performed by two evaluators: physiotherapists with at least two years of experience who had been trained to carry out evaluations. We calculated descriptive statistics (mean and standard deviation) for each patient's age and frequency distributions for spine deformity, type of deformity, motor function (Vignos scale) and presence of gait. We also calculated separate and combined frequency distributions for evaluators 1 and 2 for the following variables: trunk control level, static control level, active control level, reactive control level, cervical motion limitation and gait.

Inter-rater agreement for the variables of interest was assessed using the kappa statistics (weak agreement: $\mathrm{k}<0.21$; fair agreement: $\mathrm{k}=0.21$ to 0.40 ; moderate agreement: $\mathrm{k}=0.41$ to 0.6 ; strong agreement: $\mathrm{k}=0.61$ to 0.81 ; very strong agreement: $\mathrm{k}=0.80$ to 1.00$)^{10}$.

Relationships between ambulation and trunk control level were evaluated using a generalised linear model for ordinal variables.

All analyses were carried out using the significance level at $\mathrm{p}<0.05$.

\section{RESULTS}

The Figure shows that patients with the same functional level may have different levels of trunk control. It is 
noteworthy that patients with more advanced disease were more likely to show poor trunk control. However, $54.5 \%$ of patients classified as Vignos level 7 had total trunk control.

The frequency distribution for Vignos levels indicated that $82 \%$ of patients were classified as Vignos level 7 or 8 ; $8 \%$ as Vignos level 1; $8 \%$ as Vignos level 2 and $2 \%$ as Vignos level 3. Forty-one patients (about $82 \%$ ) were unable to walk; only nine were ambulant. Half of the non-ambulant patients (53.6\%) had trunk control level 1 and $18 \%$ of ambulant patients had full trunk control (level 7); however $66.6 \%$ of patients with full trunk control were non-ambulant.

The majority of patients ( $72 \%$ ) had some sort of spinal deformity. In $66 \%$ of all patients scoliosis was the primary deformity; kyphosis or hyper-lordosis was the primary deformity in $4 \%$ and $2 \%$ respectively.

Ambulant patients had a higher trunk control level than non-ambulant patients $(\mathrm{p}=0.003)$.

Analysis of inter-rater agreement (Table) indicated very strong agreement for the variables of trunk control level and reactive trunk control, and strong agreement for limitation of cervical rotation; there was $100 \%$ agreement on the variables of static trunk control and active trunk control.

\section{DISCUSSION}

The SATCo is a valuable tool for evaluating trunk control in DMD patients. Our results suggest that the level of functional trunk control is consistent with scores on the Vignos staging scale, which does not measure specific motor abnormalities or the quality of movements performed in different activities. The SATCo provides more detailed information on trunk control, which can be used in treatment planning.

Trunk control is a basic motor ability that is crucial in a variety of daily activities, requiring the interaction of neural and musculoskeletal systems ${ }^{8,11}$. Our results are consistent with the notion that trunk control depends on integration of neural and musculoskeletal function. Patients with DMD who were levels 5 to 7 on the SATCo and Vignos level 1 tended to be ambulant. They were able to walk up and down stairs without using a railing for support and were independent in activities of daily living. On the other hand, patients at SATCo level 1 and Vignos level 7 or 8 were non-ambulant, needing support to remain upright in a wheelchair and are dependent on caregivers to perform activities of daily living.

Anticipatory postural adjustments in the hip and trunk, which are responsible for maintaining balance during the various tasks, are needed to carry out voluntary movements ${ }^{12}$. Progressive muscle weakness in DMD patients destabilises posture by interfering with limb movements. Massion ${ }^{13}$ pointed out that stable control was important for activities involving upper limb movements. The axial and proximal muscles support the distal segments of upper limbs, thus enabling manipulation of the environment, when grasping and holding objects. Our results show that $66.6 \%$ of all DMD patients who had full trunk control (SATCo level 7) and Vignos level 7 were non-ambulant. This indicates that although they were dependent on a wheelchair for ambulation, they were independent in tasks performed with upper limbs.

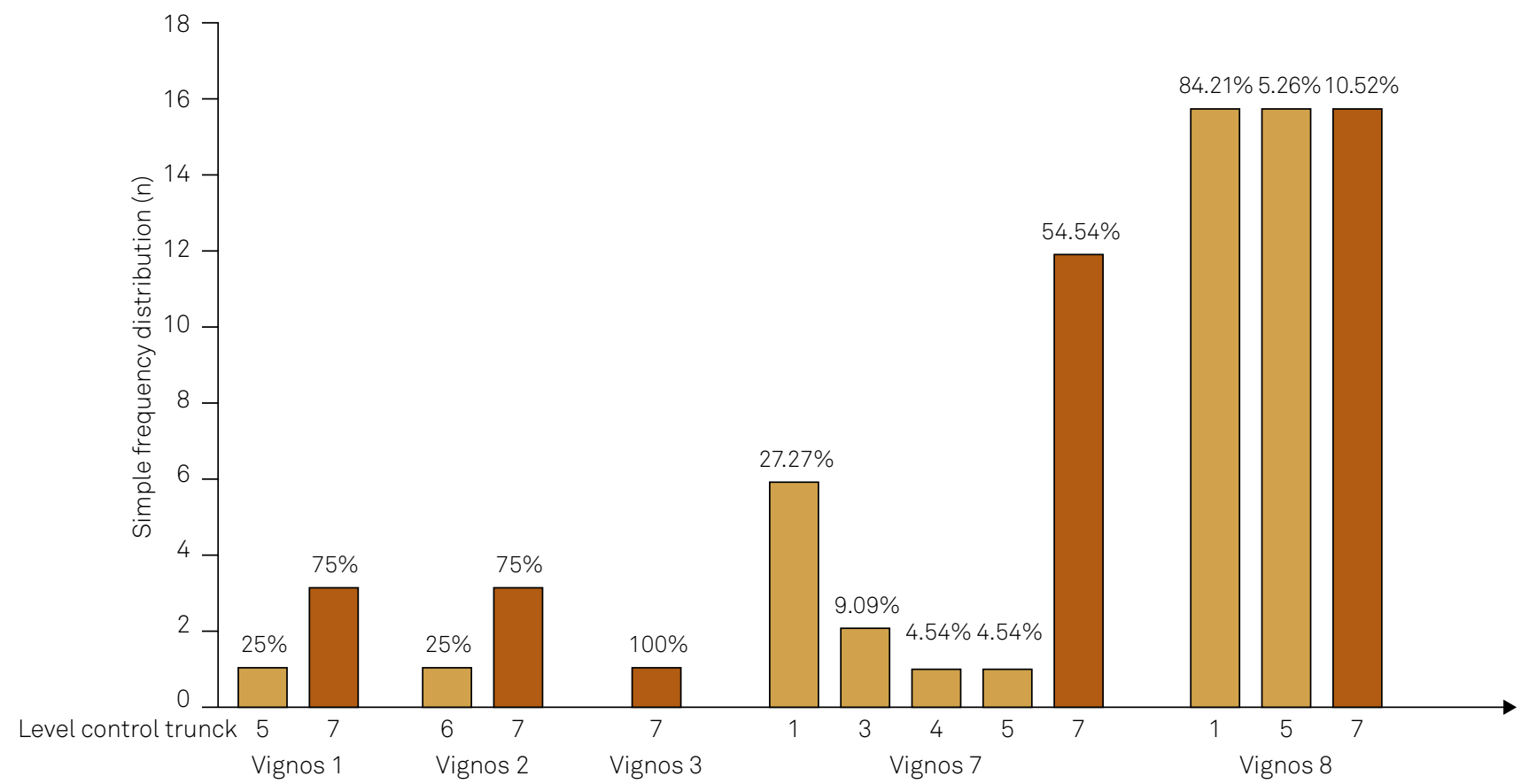

Figure. Simple frequency distribution ( $\mathrm{n}$ and percentage) comparing trunk control (1: head control; 2: upper chest control; 3: medium thoracic control; 4: lower thoracic control; 5: upper lumbar-control; 6: lower lumbar control, 7: full trunk control) and Vignos level. 
Table. Consistency between examiners.

\begin{tabular}{lccc} 
Variables & Kappa & \multicolumn{2}{c}{$\begin{array}{c}\text { Confidence } \\
\text { interval }\end{array}$} \\
\hline Trunk control level & 0.901 & 0.831 & 1.000 \\
Static & - & - & - \\
Active & - & - & - \\
Reactive & 0.959 & 0.855 & 1.000 \\
Limitation of cervical rotation & 0.615 & 0.416 & 0.802 \\
\hline
\end{tabular}

We also found that ambulant patients tended to have better control than non-ambulant patients. However, more than half of the DMD patients with full trunk control were non-ambulant. Although trunk control is essential for walking ${ }^{14}$, weakness in the muscles of the pelvic girdle and lower limbs does not, at least for a time, prevent the development of motor skills.

In most cases, the pattern of progression of muscle weakness in patients with DMD is symmetrical and proximal to distal; the pelvis and lower limbs tend to be affected early in the course of the disease. As patients age, the muscle weakness undermines motor functions and they become unable to walk; as the strength of muscles in the trunk and upper limbs decreases they become dependent on assistance for activities of daily living ${ }^{15}$. The majority of our sample $(84.2 \%)$ could only remain in the SATCo test position when their upper limbs were supported on a table surface, i.e.: they had trunk control level 1 (head control only) and a Vignos level of 8, indicating that they were able to stay upright in a wheelchair, but were not able to perform activities of daily living independently. Evaluation of SATCo levels 2 to 7 required the patient to keep the upper limbs in shoulder abduction with unsupported elbow flexion and, for the majority of our sample, this was not possible. In some cases this was the result of weakness affecting the shoulder girdle or the muscles of the upper limbs and trunk.

The DMD literature suggests that treatments have changed the course of the disease. The lifespan of DMD patients is longer owing to the commitment of multidisciplinary teams to improving their quality of life. Some studies suggest that the use of physiotherapy to retard the loss of motor function ${ }^{16}$ and delay cardiorespiratory complications has increased survival times by at least ten years ${ }^{17,18}$. The mean age of the patients in our sample was 16.7 years and this may have been a factor in the high percentage of non-ambulant patients and patients at Vignos levels 7 and 8 .

Spinal deformities are responsible for muscle imbalances and changes of postural control and trunk alignment ${ }^{19,20}$.
Most of the patients in our sample had some form of spine deformity; this is common in DMD owing to the progressive muscle weakening and consequent muscle contractures ${ }^{15}$. These changes occur in the spinal column confining most of them to a wheelchair ${ }^{2,15}$.

There was 'very strong' inter-rater agreement on the assessments of trunk control level and reactive trunk control and $100 \%$ concordance on assessments of static and active trunk control. Butler et al. ${ }^{7}$ also reported that patients with all-modes trunk control or no-modes control at a specific level were easier to identify and score. It appears that patients who had all-modes trunk control (static, active and reactive control) at a given level were easier to rate than those who were at different levels for the various modes of trunk control.

There was 'strong' inter-rater agreement on cervical rotation limitation. Tarini et al. ${ }^{21}$ showed that the limitation of cervical movement interfered with the functioning of proprioceptors and triggered changes in balance and postural control. Some authors consider the head the most important trunk segment, owing to the presence of the sensory organs of the visual and vestibular systems, which are critical to postural control ${ }^{8}$.

The analysis of inter-rater agreement confirmed that the SATCo offers a reliable method of assessing trunk control in patients with DMD. Furthermore, the instructions administering and scoring the test are clear and consistent ${ }^{7}$. The SATCo scale for trunk control evaluation can therefore be recommended as a complementary tool for identifying changes in status and for providing the information about function that is needed to develop tailored rehabilitation programs.

To improve the usability of the SATCo scale for patients with DMD, adjustments are required. This would enable the evaluation of patients at lower amplitudes of abduction and shoulder flexion, but would still ensure that the upper limbs cannot rest on the lower limbs to compensate for lack of trunk control. These adjustments are necessary because patients with DMD have much more fatigue and muscle weakness in the upper limbs than patients with non-progressive motor disorders - the population for whom the scale was developed ${ }^{7}$.

In conclusion, patients at the same stage of DMD may have different levels of trunk control; however patients with poor trunk control and hence lower SATCo scores have more advanced disease, as indexed by their Vignos level. Ambulant patients had better trunk control than non-ambulant patients, but more than half the patients with full trunk control were non-ambulant.

The SATCo scale had strong inter-rater reliability in this population.

\section{References}

1. Flaningan KM. The muscular dystrophies. Sem Neurol. 2012;32(3):255-63. doi:10.1055/s-0032-1329199

2. Kinali M, Main M, Mercuri E, Muntoni F. Evolution of abnormal postures in Duchenne muscular dystrophy. Ann Indian Acad Neurol. 2007;10(5):44-54.
3. Groot L. The posture and motility in preterm infants. Dev Med Child Neurol. 2000;42(1):65-8. doi 10.1111/j.1469-8749.2000.tb00028.x

4. Assaiante C, Mallau S, Viel S, Jover M, Schmitz C. Development of postural control in healthy children: a functional approach. Neural Plast. 2005;12(2-3):109-18. doi 10.1155/NP.2005.109 
5. Torriani C, Queiroz SS, Cyrillo FN, Monteiro CBM, Fernandes S, Padovan BB et al. Correlação entre transferência de peso sentado e alteração sensorial em região glútea em pacientes hemiplégicos/paréticos. Rev Neurocienc. 2005;13(3):117-21.

6. Santos NM, Rezende MM, Terni A, Hayashi MCB, Fávero FM, Quadros AAJ et al. Perfil clínico e funcional dos pacientes com distrofia muscular de Duchenne assistidos na Associação Brasileira de Distrofia Muscular (ABDIM). Rev Neurocienc. 2006;14(1):15-22.

7. Butler P, Saavedra MS, Sofranac MM, Jarvis MS, Woollacott M. Refinement, reliability and validity of the segmental assessment of trunk control (SATCO). Pediatr Physical Ther. 2010;22(3):246-57. doi 10.1097/PEP.0b013e3181e69490

8. Shumway-Cook A, Woollacott M. Motor control: theory and practical applications. 4th ed. Baltimore: Williams and Wilkins; 2010.

9. Vignos PJ Jr, Archibald KC. Maintenance of ambulation in childhood muscular dystrophy.J Chron Dis. 1960;12(2):273-90. doi:10.1016/0021-9681(60)90105-3

10. Altman DO. Practical statistics for medical research. 2nd ed. London: Chapman Hall; 1993.

11. Campos D, Santos DCC. Controle postural e motricidade apendicular nos primeiros anos de vida. Fisioter Mov. 2005;18(3):71-7.

12. Neumann DA. Cinesiologia do aparelho musculoesquelético: fundamentos para reabilitação. 2nd ed. São Paulo: Mosby-Elsevier; 2011.

13. Massion J. Postural control systems in developmental perspective. Neurosci Biobehav Rev. 1998;22(4):465-72.
14. Bouisset S, Zattara MA. A sequence of postural movements precedes voluntary movement. Neurosc Letters. 1981;22(3):263-70. doi:10.1016/0304-3940(81)90117-8

15. Caromano FA. Características do portador de distrofia muscular de Duchenne: Revisão. Arq Ciênc Saude Unipar. 1999;3(3):211-8.

16. Carbonero FC, Zago GM, Campos D. Tecnologia assistiva na distrofia muscular de Duchenne: aplicabilidade e benefícios. Rev Neurociênc. 2012;20(1):109-16.

17. Ramos FAB, Ordonho MC, Pinto TCVR, Lima CA, Vasconcelos CR, Silva DAL. Avaliação da força muscular respiratória e do peak flow em pacientes com distrofia muscular do tipo Duchenne submetidos à ventilação não invasiva e à hidroterapia. Pulmão RJ. 2008;17(2-4):81-6.

18. Fonseca JG, Machado MJF, Ferraz CLMS. Distrofia muscular de Duchenne: complicações respiratórias e seu tratamento. Rev Ciênc Méd. 2007;16(2):109-20.

19. Bassani E, Candotti CT, Pasini M, Melo M, La Torre M. Avaliação da ativação neuromuscular em indivíduos com escoliose através da eletromiografia de superfície. Rev Bras Fisioter. 2008;12(1):13-9. doi:10.1590/\$1413-35552008000100004

20. Fernandes MV, Fernandes AO, Franco RC, Golin MO, Santos LA, Setter CM et al. Adequações posturais em cadeira de rodas: prevenção de deformidades na paralisia cerebral. Rev Neurociênc. 2007;15(4):292-296.

21. Tarini VAF, Vilas L, Cunha MCB, Oliveira ASB. 0 exercício em doenças neuromusculares. Rev Neurociênc. 2005;13(2):67-73. 